\title{
Sound in Amsterdam During the Late Nineteenth and Early Twentieth Centuries
}

\author{
Annelies Jacobs
}

HCM 7: 538-546

DOI: $10.18352 / \mathrm{hcm} .571$

\begin{abstract}
This paper deals with sound as part of everyday urban life, based on Amsterdam during the late nineteenth and early twentieth centuries. Although it is commonly held that modern cities have grown noisier as a result of their expansion and the growth of industry and technology, we actually know very little about the urban sounds of the past. We know even less about the manner in which it was perceived and valued by contemporaries. This article poses three questions. Which sounds were produced in Amsterdam in the past? Which meanings did contemporaries attribute to these sounds? And which the role did particular sounds play in the debate on city life? To answer these questions, the article makes use of an analytical framework that allows us to look at soundscapes from the point of view of the ecology of sound, the semiotics of sound and the politics of sound.
\end{abstract}

Keywords: Amsterdam, noise, soundscapes, urban life, urban sound

\section{Introduction ${ }^{\mathrm{I}}$}

It is commonly assumed that modern cities have grown noisier due to the expansion, industrialization and 'technologization' of society. ${ }^{2}$ The continuous emergence of new sources of sound, as well as our limited ability to recall vanished sources of sound, has resulted in the 
assumption that life used to be quieter in the past. Yet we know very little about the urban sounds of the past or the role of sounds and noise in the everyday life of city residents. In what follows, I will show that it is insufficient to pay attention only to sources of sound in order to make claims about levels of sound or noise, whether in the past or in the present.

This article deals with sound as part of everyday urban life in Amsterdam during the late nineteenth and early twentieth centuries. It takes its cue from the renewed attention paid to the role of sounds in our everyday surroundings since the I970s. At that time, composer and environmental activist Raymond Murray Schafer introduced the concept of 'soundscape'. ${ }^{3}$ This gave rise to the interdisciplinary field of Sound Studies, which investigates the production and consumption of music, sound, noise and silence, in different periods and societies.

The concept of 'soundscape' refers both to all the sounds that permanently surround us and to the ways in which human beings actively perceive that outside world and give meaning to it. ${ }^{4}$ Following this definition, I have tried to map the interconnection between the urban sounds produced in a particular era, and the role and meaning attributed to these sounds in daily life. In addition, I have attempted to identify the mechanisms that explain why some sounds receive attention and are potentially declared undesirable (or are characterized as noise), while other, seemingly similar sounds are ignored.

To gain insight into the ways and degrees in which sounds have played a role in daily life in Amsterdam, I examined texts from a variety of nonfiction genres, including newspaper articles, letters to the editor, municipal reports, travel accounts, published memoirs and unpublished diaries. They all touch on the city's everyday functioning in some way or other. But because they did not cover all sounds produced in the city, I also looked at the literature on activities and the material aspects of everyday life in Amsterdam. The latter allowed me to establish which sounds residents or visitors of the city could have heard.

The research focuses on three periods, which coincide with changes in sound and noise: I875-I895, I9I8-I940 and I940-I945. During the final quarter of the nineteenth century, Amsterdam witnessed a rapid growth in population, industry and technology; in many ways its urban sounds will have been those of a decidedly 'modern' city. This trend of 
expansion and development was sustained during the interwar period (the I920s and I930s), when the role of sound and noise in discussions on urban life increased substantially. World War II also presents an interesting case study because the city suddenly had to deal with a host of altogether new sounds, radically altered meanings of sounds as well as the disappearance of familiar ones.

My analytical framework highlights three perspectives: the ecology of sound, the semiotics of sound and the politics of sound. ${ }^{5}$ This tripartite framework enables a better understanding of the complex and changeable relationship between sound, the meanings of sound and the interventions in sound. The sounds 'produced' in people's everyday living environment is referred to as the 'ecology of sound'. The 'semiotics of sound' emphasizes the role of the meanings of sound by exploring the way urban sounds were discussed and which meanings were attached to them. The 'politics of sound' focuses on sound as an aspect of political and social issues and policies. What was the role of sound in attracting attention to particular views or situations? How were interventions proposed or implemented to get rid of urban sounds as a nuisance? Applying this framework allows me to discuss the interconnection between sounds, the sounds that received attention or were ignored, and the sounds that triggered particular interventions.

\section{Urban Sound in the Late Nineteenth Century}

Between I 875 and I 895, Amsterdam saw a strong growth in population, trade, business and new forms of industry, some of which embraced production processes powered by steam engines. This growth in business activity also meant a higher circulation of traffic, that is, more pedestrians, handcarts and horse-drawn trucks, trams and carriages on the streets, and occasionally one could even see (and hear) a steam ship on one of the city's waterways. Initially, most of this urban activity took place in what today is Amsterdam's inner city, the area within the curve of a major canal (the Singelgracht). This is where the largest number of houses were to be found, even though the area could barely accommodate the growing number of residents. Many of them lived squeezed together in single-room apartments, which sometimes also 
doubled as work spaces. Where living and working did not occupy the same space, people needed to have a job nearby, in a shop or a workplace they could easily reach by foot, for there were no safe and affordable bicycles yet, while commuting by tram was too expensive for the average worker.

Against the backdrop of all sorts of bustling activity and the rather miserable living conditions of a substantial share of the local population, texts from this period devote much attention to the human voice, as well as to bells and music. Sounds of traffic and sounds of handiwork and industrial activity are much less prominent. Thinking and writing about sound still reflected an older notion of sound, based on a fundamental contrast between music and all other sounds. ${ }^{6}$ That is why musical terms were used so often, while many of today's words for sounds had another meaning. Words like 'noise' (in Dutch: lawaai) and 'din' (herrie), which could refer to a racket, were used in particular to connote lack of order, expressions of protest, a divergence of opinion or claptrap. The word 'sound' (geluid) was often used to refer to a singer's voice, who produced a 'nice sound' (hij of zij heeft een mooi geluid). Where we would use 'noise', between I875 and I895 people used words such as 'buzz' (geraas) and 'roar' (gedruisch).

The fact that people thought about sound in terms of music and non-music seems to suggest that music represented an ideal sound, and that all other sounds were of lesser quality, if not simply banal. Given this logic, people were more likely to pay attention to singing voices and musical instruments, as these were admired or valued. Less desirable sounds included, for instance, talking voices and carillon music, which kept foreign visitors from sleeping and gave them cause to complain about the unmusical ears and voices of the Dutch. Residents of Amsterdam, in turn, mostly complained about the voices and music of the 'lesser people' or the 'mob', a segment of the population that ought to be 'compliant and meek'. When they made themselves heard, as 'rough blokes, howling vendors and shouting street urchins', for instance, this was seen as eroding the established order and its civilization. This also makes it understandable that the noise of factories was hardly seen as a problem. In fact, unlike the 'reprehensible tunes' of the workers, it generated little public attention. The still substantial gap between working class and bourgeoisie is relevant since the views and opinions voiced in the texts were largely those of educated residents 
or travellers; as working-class residents were much less likely to write books or letters to newspapers.

\section{Urban Sound in the Interwar Period}

Compared to the late nineteenth century, the discourse on sound and the city took on a quite different character in the interwar period. In the I 920 and I930s, sound was increasingly approached from a physical and/or technological angle, marked by vibrations and particular intensities, and affecting the human ear and 'nerves'. ${ }^{7}$ Engineers developed several methods and units to measure sound, including the decibel. ${ }^{8}$ In contrast to the late-nineteenth-century discourse on sound, the words 'sound', 'din' and 'street noise' (straat lawaai) were now used in ways familiar to us today.

The sounds of urban traffic had changed significantly since the late nineteenth century. By the I930s, many streets were paved with asphalt and wheels came with pneumatic tires. This partly suppressed the noise of moving vehicles. At the same time, however, the horse-drawn trams, cars and carriages had been replaced by electric trams, trucks and cars, while in absolute terms the number of vehicles had gone up significantly. Because these sources of sound, taken together, contributed to the masking of separate sounds, while much traffic moved along at greater speeds, vehicles needed to signal their presence through bells and honking. Also, horses and carriages could still be seen and heard in the city, as could handcarts and hawkers. The large pack of bicyclists was new as well to the I930s; together with the expansion of the tram network, they played a major role in commuter traffic. The intensity of traffic and the much wider spectrum of speeds called for a different conduct in the use of streets. Well into the I930s this process of change was accompanied by much honking and sounding of bells, as well as by discussion about the need for, and the meaning and nuisance of, such deliberate, loud sounds.

Moreover, living and working increasingly took place in separate urban quarters. Factories and businesses no longer had to be situated at walking distance, and the city's expansion through annexation of surrounding municipalities gave rise to a band of new, partly suburban neighbourhoods around the old inner city. In these new city 
neighbourhoods, local residents, who used to live in the inner city's cramped communities and deplorable houses, lived in more spacious homes and a relatively quieter environment. Furthermore, the rise of prosperity and regulation of labour conditions resulted in an increase of leisure.

In such silence and peacefulness potential sounds were more intrusive, so that noise by neighbours much easier became a source of irritation. Furthermore, the strict class distinctions gradually receded to the background in favour of a much more diffuse yet also harder to fathom social structure. Popular media such as newspapers and radio frequently reported on the bright and not-so-bright sides of America's dazzling metropolitan life. In this context undesirable sounds in Amsterdam were no longer connected to the 'mob', but, after the American model, to the 'masses'. The latter, through their 'inborn rudeness', let themselves get carried away by jazz music, improper dancing, cinema and other 'cheap' entertainment. They were perceived, in other words, as loud and noisy people, who were incapable of responsibly handling their radio set, gramophone, motorcycle, or car horn.

\section{Urban Sound During the War}

World War II announced itself in Amsterdam by the nightly sounds of aircraft and of anti-aircraft guns. For a large number of residents this noise, together with the air-raid sirens, constituted the most direct experience of war violence in the days prior to the country's surrender. After German troops had entered the city on I 5 May I940, daily life seemed more or less restored. People were struck by the relative silence in the city; in contrast to the pre-war period, the noise of cars and buses was now largely absent.

The outbreak of the war had caused abrupt changes in the meaning of particular sounds; the noise of aircraft, for instance, had turned into a warning for potentially life-threatening situations. The Dutch surrender also gave rise to new meanings. Suddenly, for example, the antiaircraft guns were aimed at 'friendly forces' rather than the 'enemy'. This caused people to listen differently, even if the noise itself or the dangers involved may have been quite similar. 
The sounds of war activities also gave rise to new expressions: the anti-aircraft guns 'barked' (blaffen) or 'blared' (tetteren), and the sirens 'blared' (loeien) and 'wailed' (huilen). The discourse on urban sounds changed as abruptly as the meaning of particular sounds, even if there was no change in the physical nature of the sound or the language used to describe it. The noises of traffic, which during the interwar era gave rise to much discussion and complaining, were now dearly missed. Likewise, neighbourly noise was no longer a reason for complaining. It served rather as a reassuring sign of the neighbours' presence, or, in a situation where neighbours willingly or unwillingly posed a risk, as a source of information. As the war progressed, the silence in the city became a sign of the involuntary departure of Jewish residents and the uncertain fate awaiting them. Aside from the loud noises of aircraft, anti-aircraft guns, sirens and shooting, silence likewise evolved into a quite intense 'sound' of war.

Adults, sometimes much to their surprise, proved capable of adapting to the sounds of war swiftly, but for youngsters and children the powerful noise of anti-aircraft guns, explosions and sirens continued to be frightening. Most city residents did not welcome the German presence, and this also applied to the sounds that accompanied the occupation. As a result, these were either ignored in the discourse or characterized by words such as shouting, yelling or clamour. Apart from this form of 'sound politics', where normative language was used to describe a repugnant situation or despicable conduct, both sides deployed music to practice politics during the war. While parties linked to the Germans organized musical performances and parades in town, for many local residents the national anthem and other music associated with Dutch identity became a sign of resistance and self-affirmation.

\section{Conclusion}

The three historical glimpses into the soundscapes of Amsterdam reveal that we cannot understand the changes in everyday urban life in the past only by taking into account the perspective of the soundscape we inhabit today. To bridge the gap, the analytical framework described above serves as a productive tool. It throws more light on the specific historical relations between the material aspects of the soundscape (the 
ecology of sound), the interventions in sound (the politics of sound) and the meanings involved (the semiotics of sound). The meaning attached to silence in the I920s and I930s, for example, changed during the occupation, which makes it understandable that the noise of car traffic, which used to give rise to lots of complaining, was desperately missed by residents during the war. Similarly, the increasing complaints about neighbourly noise during the interwar period did not logically follow from the city's growing population, but should be seen in the light of the fact that for the first time a large segment of the local population lived in more spacious, quiet suburban neighbourhoods.

A comparison of the three cases reveals that it would be wrong to assume that the increase in population, industry and technology automatically leads to 'more' sound, and hence to an increase in complaints about sound. Moreover, the complaints do not need to be tied directly to the sounds produced by more people, machines and workplaces. Despite the increase in industry and technology in Amsterdam between I875 and I895 and during the interwar period, the intensified noise of machines and industry failed to generate much attention.

If we compare these findings with the role of sounds and noise in our own era, it strikes one that today complaints about noise tend no longer to be framed in terms of the erosion of order and decency by marginal groups in society, or the overstimulation of the urban residents' nervous system brought about by the irresponsible behaviour of immoderate people. Instead, exposure to noise is understood in terms of illness, social disadvantage and high costs. Such a comparative approach to complaints about noise is interesting because it underscores that in each period a limited number of sounds is associated with largely abstract and uncontrollable threats and dangers. During World War II, 'silence' proved to have such function, symbolizing a threat or sense of danger because of the absence of familiar urban sounds, or because it stressed the uncertainty of the moment.

We cannot understand changes in soundscapes simply in terms of more or less urban silence, or more or less noise. Every era has sounds of its own, and words to describe these sounds, as well as ways of expressing complaints about noise or articulating views on silence. Silence may connote an oppressive sound of war but also a melancholy sense of loss in a city that used to be lively and vigorous. For this reason, claims that cities grow ever noisier or that their sounds get 'worse' 
all the time need largely to be understood as a rhetorical strategy to express discontent with the present.

\section{Notes}

I This article draws in large measure on the summary of my $\mathrm{PhD}$ thesis Het geluid van gisteren. Waarom Amsterdam vroeger ook niet stil was (Maastricht, 20I4). The research was funded by the Dutch Organisation for Scientific Research (NWO).

2 D. Hendy, Noise: A Human History of Sound and Listening (London, 20I3), xii-xiii.

3 R.M. Schafer, The Soundscape. Our Sonic Environment and the Tuning of the World (Rochester VT, I977/I994).

4 E. Thompson, The Soundscape of Modernity: Architectural Acoustics and the Culture of Listening in America, 1900-1933 (Cambridge MA, 2002).

5 A. Jacobs, 'The Silence of Amsterdam Before and During World War II: Ecology, Semiotics and Politics of Urban Sound', D. Morat (ed.), Sounds of Modern History. Auditory Cultures in I9th and 2oth Century Europe (New York, 20I4).

6 M. Rieger, 'Musik im Zeitalter von Sound. Wie Hermann von Helmholtz eine neue Ära begründete', T. Phleps and R. v. Appen (eds), Pop Sounds. Klangtexturen in der Pop- und Rockmusik. Basics - Stories - Tracks (Bielefeld, 2003), I83-96.

7 A. Dubois, 'Acoustiek en moderne bouwkunde: De strijd tegen het lawaai', Algemeen Handelsblad (08-05-1932), 27.

8 K. Bijsterveld, Mechanical Sound: Technology, Culture, and Public Problems of Noise in the Twentieth Century (Cambridge MA, 2008), I04-I IO.

\section{About the Author}

Annelies Jacobs is lecturer at the Faculty of Arts and Social Sciences at Maastricht University in the Netherlands. Trained as an architect at Eindhoven University of Technology, she received her $\mathrm{PhD}$ in Science, Technology and Society Studies at Maastricht University (Het geluid van gisteren. Waarom Amsterdam vroeger ook niet stil was ('The sound of yesterday. Why Amsterdam was not silent in the past', 20I4). 